\title{
Twenty years after 'Listening to Prozac but hearing placebo'. Do we hear placebo even louder?
}

\begin{abstract}
An active placebo is a substance that produces side effects similar to an active ingredient while not producing the same intended therapeutic effect. The aim of this study is to review the literature on the hypothesis of the active placebo response as a mechanism of action of antidepressants. It was found that persons who expect the occurrence of side effects of a pure placebo taken under the guise of an antidepressant present a higher degree of depressive symptoms than persons who do not expect the occurrence of side effects.
\end{abstract}

There are reasons to believe that the entirety or part of the difference in the effectiveness of antidepressants and placebo is due to the fact that participants of the clinical trials correctly guess which study group they have been assigned to.

\section{KEY WORDS}

antidepressants; expectations; placebo response

ORganization - 1: III Department of Psychiatry, Institute of Psychiatry and Neurology, Warsaw, Poland · 2: Institute of Psychology, Jagiellonian University, Cracow, Poland

Authors' Contributions - A: Study design - B: Data collection - C: Statistical analysis - D: Data interpretation .

E: Manuscript preparation · F: Literature search · G: Funds collection

CORRESPONDING AUTHOR - Wojciech Oronowicz-Jaśkowiak, Institute of Psychiatry and Neurology, 9 Sobieskiego Str., 02-957 Warsaw, Poland, e-mail: wojciechoronowicz@gmail.com

TO CITE THIS ARTICLE - Oronowicz-Jaśkowiak, W., \& Bąbel, P. (2019). Twenty years after 'Listening to Prozac but hearing placebo'. Do we hear placebo even louder? Health Psychology Report, 7(1), 1-8. https://doi.org/10.5114/hpr.2019.83383 RECEIVED 11.09.2018 · REVIEWED 04.11.2018 · ACCEPTED 06.12.2018 • PUBLISHED 07.03.2019 


\section{BACKGROUND}

Depressive disorder is one of the most common mental health disorders. According to the diagnostic criteria of the American Psychiatric Association, the diagnosis of major depressive disorder requires the observation of several signs and symptoms, such as low mood, excessive sleepiness or insomnia, weight loss, feeling of worthlessness, and unjustified guilt (APA, 2013). It is estimated that in the United States,
Wojciech OronowiczJaśkowiak, Przemysław Bąbel depression affects $7.00 \%$ of the population annually, and persons aged between 18 and 29 years and over 60 years are particularly vulnerable (see APA, 2013).

According to the dominant hypothesis derived from the biological theory of depression, the condition is associated with abnormal neurotransmission in the central nervous system (Beck \& Alford, 2009). It is suggested that there may be a pathologically increased sensitivity of neurotransmitter receptors in the course of depressive disorder. As neurophysiologists have proven, if the level of a neurotransmitter is adequately high, the organism downregulates the number of receptors, e.g. serotonin receptors, in order to maintain a stable neural signal (Stahl, 1994). However, if there is a deficiency of a neurotransmitter, it upregulates and increases the number of receptors, e.g. serotonin receptors. It is believed that in depression, the number of serotonin receptors is higher due to low serotonin levels. Therefore, if a person suffering from depression and having a high number of receptors is given a substance that inhibits the reuptake of the neurotransmitter, a new balance of neurotransmitters and receptors should be achieved.

Treatment methods based on the biological theory of depression include pharmacotherapy with antidepressants. Antidepressants are a heterogeneous group of medications and are believed to reduce signs and symptoms of depressive disorder (see Rybakowski, 2011). Antidepressant groups include monoamine oxidase inhibitors (MAOIs), tricyclic antidepressants (TCAs), selective serotonin reuptake inhibitors (SSRIs), and serotonin-norepinephrine reuptake inhibitors (SNRIs). These medications are frequently used in clinical practice. In the United States, sales growth of pharmacological agents, particularly antidepressants, is observed (Gu, Dillon, \& Burt, 2011).

The aim of this study is to review the hypothesis of the active placebo response as a mechanism of action of antidepressants.

\section{ACTIVE PLACEBO RESPONSE HYPOTHESIS}

The biological theory is criticized, as the main evidence supporting this theory is the claimed effectiveness of antidepressants in the treatment of depressive disorders, as well as ambiguous results of experimental studies on the effect of the medications on the receptor activity in the central nervous system (Cowen, 2008). It has been suggested that empirical evidence confirming the chemical imbalance theory is insufficient, however, it seems not to have affected its popularity (Lacasse \& Leo, 2015). In one of the most interesting studies, mice that were unable to produce serotonin were bred in order to investigate whether they would display depressive symptoms (Angoa-Pérez et al., 2014). The mice displayed compulsive and aggressive behaviors, but no signs of depression were observed. Moreover, when the mice were subjected to stress, there was no difference in behavior of normal mice and mice without serotonin receptors. The researchers concluded that serotonin cannot be the main factor contributing to the etiology or development of depressive disorder.

It should be noted that an alternative mechanism of action of antidepressants has been presented, and it does not refer to the chemical imbalance theory the active placebo response hypothesis (Kirsch, 2009; see Siwak, Oronowicz-Jaśkowiak, \& OronowiczJaśkowiak, 2017). Selected publications suggest that the effect of antidepressant treatment is indeed the same as the active placebo response, which takes place when the patient experiences side effects of taken medications (Kirsch, 2014). It is underlined that antidepressants cause a number of easily noticeable side effects, such as dry mouth (xerostomia), drowsiness, anxiety, and low libido (e.g., Hughes, Lacasse, Fuller, \& Paulding-Givens, 2017). It is suggested that if a patient discovers one of these side effects, they conclude that they are in the study group receiving the active substance, and not the placebo (Rabkin et al., 1986), which affects their expectations of the effectiveness of the treatment.

When defining the term active placebo, it can be assumed that it is an agent that does not contain any active ingredient (in this case, an antidepressant), but produces similar side effects as the active treatment (active ingredient of antidepressants) (Bąbel, 2006; Dolińska, 2011).

It is also noted that in clinical trials, the awareness of the fact that the participant may receive a placebo instead of a real medication is related to the percentage of patients that respond to treatment. The percentage of patients responding to treatment when (1) the subjects are aware of the fact that there is no possibility that they are in a group receiving a pure placebo instead of a medication, and (2) the subjects are aware of the fact that there is a possibility that they are receiving either a medication or a pure placebo was $60.00 \%$ and $46.00 \%$, respectively (Sneed et al., 2008). Recent experimental studies have shown that the therapeutic effect of selective serotonin reuptake inhibitors (escitalopram was used in the study) was two to three times higher (in terms of the reduction of signs and symptoms of depressive disorder or so- 
cial anxiety) when the patient was sure that they had received an active substance than when the patient was not sure whether they had been administered an antidepressant or a placebo (Faria et al., 2017). In addition, the study revealed that these two groups of patients were characterized by a different neural response of brain areas responsible for the interaction of cognitive and emotional processes (Faria et al., 2017). Other studies have shown that patients' expectations towards therapy have a significant influence on their depressive signs and symptoms (Rutherford et al., 2016).

The above described observations affect the outcomes of pharmacotherapy. It is reported that the higher effectiveness of active medications when compared with placebo is not caused exclusively by the suggested chemical mechanism of action of a medication. This leads to overestimating the effectiveness of pharmacotherapy (Lund, Vase, Petersen, Jensen, \& Finnerup, 2014; Kube \& Rief, 2017). The interfering factors include, among others, the conditioning process and expectations towards effectiveness of treatment (Kube \& Rief, 2017).

\section{DIRECT EVIDENCE SUPPORTING THE ACTIVE PLACEBO RESPONSE HYPOTHESIS AS A MECHANISM OF ACTION OF ANTIDEPRESSANTS}

The first scientific report that showed a clear relationship of the placebo response with the efficacy of antidepressant therapy was a meta-analysis of 19 clinical trials: Listening to Prozac but hearing placebo (Kirsch \& Sapirstein, 1998). This meta-analysis revealed a 0.90 correlation between the therapeutic effect of antidepressant treatment and the placebo response in the control group. The meta-analysis reported that antidepressants and psychotherapy all reduced depressive signs and symptoms, but the therapeutic effect of fluoxetine was stronger than the placebo response.

It must be noted that conclusions of the study by Kirsch and Sapirstein (1998) were criticized, as the method for analyzing the results that was used by the authors could result in artifacts related to the regression to the average due to comparing two groups with a high intensity of the examined feature (Dawes, 1998). Further criticism was also presented by Klein (1998), but at least some of Klein's objections regarding Kirsch's “irrelevant speculations" may not remain true today. Subsequent studies have extended the research perspective by using active placebo and different groups of patients.

A meta-analysis of 131 clinical trials that compared the therapeutic effect of selective serotonin reuptake inhibitors with pure placebo indicated that antidepressants show higher effectiveness than pure placebo; however, the difference was established to be too small to be clinically relevant (Jakobsen et al., 2017). The mean improvement difference between the groups was 1.94 on the Hamilton Depression Rating Scale, while the difference that is expected for a therapeutic method to be recognized as effective should be at least 3 points (Jakobsen et al., 2017).

A meta-analysis of 9 clinical trials in which active placebo was used indicated that antidepressant treatment is slightly more effective than the administration of active placebo $(d=0.39)$ or that the difference between the groups is not significant, depending on the data analysis approach - liberal or conservative (Moncrieff, Wessely, \& Hardy, 2004). On the other hand, another meta-analysis suggests that the lack of difference between active placebo and antidepressants may depend on a particular substance (Hieronymus, Lisinski, Nilsson, \& Eriksson, 2017). It has been observed that patients taking paroxetine and experiencing side effects had the biggest clinical improvement (when compared with patients taking pure placebo and patients taking paroxetine and not experiencing side effects); however, in the case of citalopram, the outcomes were similar for taking citalopram and experiencing side effects and taking citalopram and not experiencing side effects, and the difference between groups was not significant $(p=.140)$.

Greenberg et al. (1994) observed a significant correlation between symptom reduction and side effects of selective serotonin reuptake inhibitors. Importantly, the correlation applied both to signs observed by clinicians $(r=.85)$ and to symptoms reported by patients $(r=.96)$.

The above described studies may support the hypothesis of the active placebo response as a mechanism of action of antidepressants. However, it should be kept in mind that there are significantly fewer studies that use an active placebo than studies that use a pure placebo (Jensen, Bielefeldt, \& Hróbjartsson, 2017). Nevertheless, there is also indirect evidence supporting the hypothesis of the active placebo response as a mechanism of action of antidepressants, as will be shown in the next section.

\section{INDIRECT EVIDENCE SUPPORTING THE ACTIVE PLACEBO RESPONSE HYPOTHESIS AS A MECHANISM OF ACTION OF ANTIDEPRESSANTS}

It is believed that many pharmacological agents help reduce the severity of depression. These medications include, among others, psilocybin (Dydak, Sliwinska-Mosson, \& Milnerowicz, 2016), carbamazepine (Zhang et al., 2008), and, in combination with antidepressants: benzodiazepines (Furukawa, Streiner, Young, \& Kinoshita, 2001), thyroid hormones (Aronson, Offman, Joffe, \& Naylor, 1996), risperidone
Twenty years after 'Listening to Prozac but hearing placebo' 
(Ostroff \& Nelson, 1999), and lithium compounds (Bauer \& Döpfmer, 1999). In addition, supplementing omega-3 fatty acids is believed to reduce depression (Osher \& Belmaker, 2009). The evidence for the effectiveness of these medications, which are supposed to act independently from the chemical imbalance theory, may support the hypothesis that pharmacological treatment of depression is not specific for antidepressants.

It should also be noted that empirically supported Wojciech OronowiczJaśkowiak, Przemysław Bąbel methods of depression treatment are not limited to pharmacological agents (e.g., Rybakowski, 2011), but also include physical activity (Netz, 2017), cognitivebehavioral psychotherapy (Hofmann et al., 2012), mindfulness meditation (Ramel, Goldin, Carmona, \& McQuaid, 2004), short-term psychodynamic therapy (Driessen et al., 2010), and eye movement desensitization and reprocessing (Edmond, Rubin, \& Wambach, 1999; Capezzani et al., 2013). It must be noted that these methods are supposed to have various mechanisms of action and their characteristics differ. However, their non-specific effects enable depressive symptoms to be improved.

Some of the most interesting studies focus on the effectiveness of homeopathy, which, similarly to placebo administration, does not introduce active substances to the patient's organism (NHMRC, 2015). The results of a study with 566 patients, some of whom consulted a homeopath, suggest that homeopathy is equally effective as antidepressants in reducing depressive symptoms (measured with the PHQ-9 questionnaire) (Viksveen, Relton, \& Nicholl, 2017). Interestingly, the duration of the study was 12 months, which is unusually long for this kind of research.

Herbal preparations are also used in treatment or supportive treatment of major depressive episodes or affective disorders that are not classified as major depression, Hypericum (St. John's wort) being a notable example. Hypericum is believed to improve reuptake of serotonin, noradrenaline and dopamine (Koszewska, 2003). However, it must be noted that there is no reliable evidence to support the use of St. John's wort for depressive disorder. A study on 340 patients diagnosed with depression based on DSM-IV criteria was conducted (Hypericum Depression Trial Study Group, 2002). The patients were divided into groups taking an antidepressant (Serotax), placebo or Hypericum. After 8 weeks and 6 months of treatment, there was no difference in the outcome between groups. In other words, antidepressant, placebo, and Hypericum were all equally ineffective.

A meta-analysis on depression treatment with $\mathrm{Hy}$ pericum indicated that it presents a therapeutic effect greater than placebo and similar to antidepressants (studies included fluoxetine, sertraline, imipramine, citalopram, paroxetine, maprotiline, and amitriptyline; Ernst, 1995). Interestingly, the authors of another meta-analysis comparing the effectiveness of Hyperi- cum and placebo observed that Ernst's conclusions were essentially true, but only in the case of German patients (Linde, Berner, \& Kriston, 2008). The analysis of the participants' nationality revealed that 8 out of 11 German clinical trials reported Hypericum to be more effective than placebo, whereas none of the nonGerman studies found Hypericum to be effective. The combined effectiveness of Hypericum and placebo was significantly higher in German-speaking countries. The results of the analysis may show the role of different cultural expectations and its effect on the clinical outcomes or may indicate a different methodological approach of German researchers. On the other hand, the observed difference may be due to differences in the quality of products distributed in Germany and in other countries, resulting from using different brands containing varying doses of the supplement (see Klemow et al., 2004). In Germany, there are regulations concerning, among others, the amount of active ingredient in Hypericum supplements.

Particular attention should be drawn to the use of antidepressants in minor depressive disorder (i.e. mild, short-term depression). A meta-analysis of 6 clinical trials on the effectiveness of fluoxetine, amitriptyline and isocarboxazid in treatment of minor depression (Barbui, Cipriani, Patel, Ayuso-Mateos, \& van Ommeren, 2011) showed that treatment with these substances is no more effective than placebo. Moreover, according to the guidelines of the National Institute for Health and Care Excellence (NICE, 2009), antidepressants should not be used for treatment of mild and short-term depression, as their effectiveness compared with placebo is hard to demonstrate. Nevertheless, the Institute underlines that antidepressants may be indicated in treatment of dysthymia and other forms of mild, long-term depression.

It is also suggested that previous analyses proving the effectiveness of antidepressants are burdened with a high risk of error due to the controversies accompanying clinical trials that they were based on (Deacon \& Spielmans, 2017). The re-analysis of the effects of treatment of major depressive disorders of adolescents with paroxetine and imipramine may serve as an example (Le Noury et al., 2015). The re-analysis of the clinical data was performed by a team other than the team responsible for the primary analysis, which was sponsored by GSK Pharmaceuticals. It was proven that the interpretation method of clinical data that supported the use of paroxetine and imipramine in treatment of major depressive disorder in adolescents was faulty. In the paper by Keller et al. (2001), the endpoint of the study was modified after the trial had been completed. According to the standards for conducting clinical trials, the endpoint should be established before the onset of the trial to determine what would be considered a significant improvement in the patients' condition. In this case, without modifying primary data, the final conclusion changed - it 
was concluded that paroxetine was an effective drug, whereas the same data with the previous endpoint would have proven otherwise. It was later shown that paroxetine and imipramine were equally effective as pure placebo (Le Noury et al., 2015). Le Noury et al. (2015) also underlined the need for a greater transparency of clinical trial databases. GSK Pharmaceuticals received a major fine for marketing paroxetine as a safe drug for the treatment of major depressive disorder in adolescents (Reuters, 2015).

An analysis of the results of clinical trials on antidepressants from the years 1987-2013 was conducted in order to determine whether the differences in clinical outcome between placebo and antidepressants varies over time (Khan, Fahl Mar, Faucett, Khan Schilling, \& Brown, 2017). This study was a response to a publication cycle suggesting that over time, the therapeutic effect of antidepressant increases, but this effect was to depend exclusively on the increasing share of the placebo effect in its efficacy. It was proven that over time, the positive outcomes of both antidepressants and placebo increase to the same extent. In this analysis, the aspect of expecting certain side effects of taking placebo or medication was not discussed, as the analyzed studies did not report on side effects perceived by the patients. It is possible that if the aspect was controlled, the difference between the placebo effect and the active substance effect would increase over timeOn the other hand, Huneke et al. (2017) published an interesting experimental study, in which the relationship between emotional processing and taking a placebo was examined. Emotional processing is believed to be an adequate new index for testing antidepressant effectiveness. The participants were randomized to one of three study groups (placebo, antidepressant, no treatment) and were assessed using psychological tools evaluating emotional processing. There was no difference between the pure placebo group and the no treatment group in emotional processing. In this study, the occurrence of side effects was not controlled, and the authors are yet to present a detailed comparison of the three experimental groups and only compared placebo and no treatment groups. The results seem to contradict what we know about placebo, and it would be very interesting to see a similar study on an active placebo. If an active placebo affected emotional processing to a greater extent than a pure placebo, it would be another argument for using an active rather than a pure placebo in control groups.

\section{CONCLUSION AND FURTHER DIRECTIONS}

The arguments for the active placebo response hypothesis are based on direct and indirect evidence. Direct evidence includes a smaller number of experimental studies in which an active placebo was used which report no significant difference in outcomes of treatment with antidepressants and an active placebo. Moreover, it may be assumed that the reduction in depressive signs and symptoms can be achieved by a variety of pharmacological agents (including medications other than antidepressants), as well as by different nonpharmacological treatment methods. It seems that a common factor of all these methods is patients' or participants' conviction of their effectiveness.

It is important to conduct experimental studies in which researchers manipulate participants' expectations on the occurrence of side effects when taking antidepressants. The majority of currently available studies did not include an active placebo - only antidepressants and pure placebos were tested, and additional questionnaires were distributed in order to collect information on side effects that the participants had experienced during the trial. The awareness of the fact that when taking part in a clinical trial, one may be included either in a group receiving placebo or receiving a medication, may not be neutral to the treatment outcomes due to patients' different expectations.

It is necessary to study the frequency of patients discovering their study group assignment. According to the active placebo response theory, participants of studies guess their study group after having observed some side effects. The assumption is important for the theory; however, empirical studies are scarce.

Although the Hamilton Rating Scale for Depression (Hamilton, 1986), which can be considered a valuable diagnostic tool (Kirsch, 2009), has been frequently used in drug efficacy studies, it seems appropriate to test the hypothesis with other depression scales. It cannot be doubted that the Hamilton Rating Scale for Depression is an adequate tool for measuring depressive signs and symptoms, as it is characterized by good psychometric properties, and the evaluation is performed by a clinician who assesses the symptoms by observing the patient (Gençöz, Gençöz, \& Soykan, 2007). However, the inclusion of more tools could thus support the ecological validity of the active placebo response hypothesis. Furthermore, it has been proven that self-rated scales might be more sensitive than clinician-rated scales in milder forms of depression (Cuijpers, Li, Hofmann, \& Andersson, 2010).

\section{References}

American Psychiatric Association (2013). Diagnostic and Statistical Manual of Mental Disorders (DSM-5). Washington: APA Publishing.

Angoa-Pérez, M., Kane, M. J., Briggs, D. I., HerreraMundo, N., Sykes, C. E., Francescutti, D. M., \& Kuhn, D. M. (2014). Mice genetically depleted of brain serotonin do not display a depression-like
Twenty years after 'Listening to Prozac but hearing placebo' 
behavioral phenotype. ACS chemical neuroscience, 5, 908-919. https://doi.org/10.1021/cn500096g

Aronson, R., Offman, H. J., Joffe, R. T., \& Naylor, C. D. (1996). Triiodothyronine augmentation in the treatment of refractory depression: a meta-analysis. Archives of General Psychiatry, 53, 842-848. https:// doi.org/10.1001/archpsyc. 1996.01830090090013

Barbui, C., Cipriani, A., Patel, V., Ayuso-Mateos, J. L., \& van Ommeren, M. (2011). Efficacy of antidepressants and benzodiazepines in minor depression: sys-

Wojciech OronowiczJaśkowiak, Przemysław Bąbel tematic review and meta-analysis. British Journal of Psychiatry, 198, 11-16. https://doi.org/10.1192/bjp. bp. 109.076448

Bauer, M., \& Döpfmer, S. (1999). Lithium augmentation in treatment-resistant depression: metaanalysis of placebo-controlled studies. Journal of Clinical Psychopharmacology, 19, 427-434. https:// doi.org/10.1097/00004714-199910000-00006

Bąbel, P. (2006). Placebo i nocebo. Próba integracji [Placebo and nocebo. An attempt to integrate the terms]. Przegląd Psychologiczny, 49, 141-156.

Beck, A. T., \& Alford, B. A. (2009). Depression: Causes and treatment. Philadelphia: University of Pennsylvania Press.

Capezzani, L., Ostacoli, L., Cavallo, M., Carletto, S., Fernandez, I., Solomon, R., Pagani, M., \& Cantelmi, T. (2013). EMDR and CBT for cancer patients: Comparative study of effects on PTSD, anxiety, and depression. Journal of EMDR Practice and Research, 7, 134-143. https://doi.org/10.1891/19333196.7.3.134

Cowen, P. J. (2008). Serotonin and depression: pathophysiological mechanism or marketing myth? Trends in Pharmacological Sciences, 29, 433-436. https://doi.org/10.1016/j.tips.2008.05.004

Cuijpers, P., Li, J., Hofmann, S. G., \& Andersson, G. (2010). Self-reported versus clinician-rated symptoms of depression as outcome measures in psychotherapy research on depression: a metaanalysis. Clinical Psychology Review, 30, 768-778. https://doi.org/10.1016/j.cpr.2010.06.001

Dawes, R. M. (1998). "Listening to Prozac but hearing placebo": Commentary on Kirsch and Sapirstein. Prevention \& Treatment, 1. https://doi. org/10.1037//1522-3736.1.1.15c

Deacon, B. J., \& Spielmans, G. I. (2017). Is the efficacy of "antidepressant" medications overrated? In S. O. Lilienfeld \& I. D. Waldman (Eds.), Psychological science under scrutiny (pp. 250-270). Hoboken, NJ: John Wiley \& Sons, Inc.

Dolińska, B. (2011). Placebo. Dlaczego działa coś, co nie dziata? [Placebo. Why it works when it doesn't work?]. Sopot: Smak Słowa.

Driessen, E., Cuijpers, P., de Maat, S. C., Abbass, A. A., de Jonghe, F., \& Dekker, J. J. (2010). The efficacy of short-term psychodynamic psychotherapy for depression: a meta-analysis. Clinical Psychology Review, 30, 25-36.

Dydak, K., Sliwinska-Mosson, M., \& Milnerowicz, H. (2016). Psilocybin as an alternative medicine for patients suffering from depression. Psychiatria i Psychologia Kliniczna, 16, 165-170. https://doi. org/10.15557/PiPK.2016.0023

Edmond, T., Rubin, A., \& Wambach, K. G. (1999). The effectiveness of EMDR with adult female survivors of childhood sexual abuse. Social Work Research, 23, 103-116.

Ernst, E. (1995). St. John's Wort, an anti-depressant? A systematic, criteria-based review. Phytomedicine, 2, 67-71.

Faria, V., Gingnell, M., Hoppe, J. M., Hjorth, O., Alaie, I., Frick, A., Hultberg, S., Wahlstedt, K., Engman, J., Månsson, K. N. T., Carlbring, P., Andersson, G., Reis, M., Larsson, E. M., Fredrikson, \& M., Furmark, T. (2017). Do you believe it? Verbal suggestions influence the clinical and neural effects of escitalopram in social anxiety disorder: a randomized trial. EBioMedicine, 24, 179-188. https://doi. org/10.1016/j.ebiom.2017.09.031

Furukawa, T. A., Streiner, D., Young, L. T., \& Kinoshita, Y. (2001). Antidepressants plus benzodiazepines for major depression. London: The Cochrane Library.

Gençöz, F., Gençöz, T., \& Soykan, A. (2007). Psychometric properties of the Hamilton Depression Rating Scale and other physician-rated psychiatric scales for the assessment of depression in ESRD patients undergoing hemodialysis in Turkey. Psychology, Health \& Medicine, 12, 450-459. https://doi.org/10.1080/13548500600892054

Greenberg, R. P., Bornstein, R. F., Fisher, S., Zborowski, M. J., \& Greenberg, M. D. (1994). A meta-analysis of fluoxetine outcome in the treatment of depression. The Journal of Nervous and Mental Disease, 182, 547-551. https://doi.org/10.1097/00005053199410000-00003

Gu, Q., Dillon, C. F., \& Burt, V. L. (2010). Prescription drug use continues to increase: US prescription drug data for 2007-2008. NCHS Data Brief, 42, 1-8.

Hamilton, M. (1986). The Hamilton rating scale for depression. In M. Hamilton (Ed.), Assessment of depression (pp. 143-152). Heidelberg: Springer.

Hieronymus, F., Lisinski, A., Nilsson, S., \& Eriksson, E. (2017). Efficacy of selective serotonin reuptake inhibitors in the absence of side effects: a mega-analysis of citalopram and paroxetine in adult depression. Molecular Psychiatry, 23, 1731-1736. https:// doi.org/10.1038/mp.2017.147

Hofmann, S. G., Asnaani, A., Vonk, I. J., Sawyer, A.T., \& Fang, A. (2012). The efficacy of cognitive behavioral therapy: A review of meta-analyses. Cognitive Therapy and Research, 36, 427-440.

Hughes, S., Lacasse, J., Fuller, R. R., \& Paulding-Givens, J. (2017). Adverse effects and treatment satisfaction among online users of four antidepressants. Psychiatry Research, 255, 78-86. https://doi. org/10.1016/j.psychres.2017.05.021 
Huneke, N. T., Walsh, A. E., Brown, R., Browning, M., \& Harmer, C. J. (2017). No evidence for an acute placebo response on emotional processing in healthy volunteers. Journal of Psychopharmacology, 31, 1578-1587.

Hypericum Depression Trial Study Group (2002). Effect of Hypericum perforatum (St John's wort) in major depressive disorder: a randomized controlled trial. Journal of the American Medical Association, 287, 1807-1814. https://doi.org/10.1001/ jama.287.14.1807

Jakobsen, J. C., Katakam, K. K., Schou, A., Hellmuth, S. G., Stallknecht, S. E., Leth-Møller, K., \& Krogh, J. (2017). Selective serotonin reuptake inhibitors versus placebo in patients with major depressive disorder. A systematic review with meta-analysis and trial sequential analysis. BMC Psychiatry, 17, 58. https://doi. org/10.1186/s12888-016-1173-2

Jensen, J. S., Bielefeldt, A. Ø., \& Hróbjartsson, A. (2017). Active placebo control groups of pharmacological interventions were rarely used but merited serious consideration: A methodological overview. Journal of Clinical Epidemiology, 87, 35-46. https:// doi.org/10.1016/j.jclinepi.2017.03.001

Keller, M. B., Ryan, N. D., Strober, M., Klein, R. G., Kutcher, S. P., Birmaher, B., Hagino, O. R., Koplewicz, H., Carlson, G. A., Clarke, G. N., Emslie, G. J., Feinberg, D., Geller, B., Kusumakar, V., Papatheodorou, G., Sack, W. H., Sweeney, M., Wagner, K. D., Weller, E. B., Winters, N. C., Oakes, R., \& McCafferty, J. P. (2001). Efficacy of paroxetine in the treatment of adolescent major depression: a randomized, controlled trial. Journal of the American Academy of Child \& Adolescent Psychiatry, 40, 762-772.

Khan, A., Fahl Mar, K., Faucett, J., Khan Schilling, S., \& Brown, W. A. (2017). Has the rising placebo response impacted antidepressant clinical trial outcome? Data from the US Food and Drug Administration 1987-2013. World Psychiatry, 16, 181-192.

Kirsch, I. (2014). Antidepressants and the placebo response. Zeitschrift für Psychologie, 222, 128-134. https://doi.org/10.1027/2151-2604/a000176

Kirsch, I. (2009). The Emperor's New Drugs. London: The Bodley Head.

Kirsch, I., \& Sapirstein, G. (1998). Listening to Prozac but hearing placebo: A meta-analysis of antidepressant medication. Prevention \& Treatment, 1. https://doi.org/10.1037/1522-3736.1.1.12a

Klein, D. F. (1998). Listening to meta-analysis but hearing bias. Prevention \& Treatment, 1. https:// doi.org/10.1037/1522-3736.1.1.16c

Klemow, K. M., Bilbow, E., Grasso, D., Jones, K., McDermott, J., \& Pape, E. (2011). Medical attributes of St. John's wort (Hypericum perforatum). In I. F. F. Benzie \& S. Wachtel-Galor (Eds.), Herbal Medicine (2nd ed., pp. 757-780). Boca Raton, FL: CRC Press/Taylor \& Francis.
Koszewska, I. (2003). Dziurawiec zwyczajny w leczeniu depresji [St. John's wort in the treatment of depression]. Farmakoterapia w Psychiatrii i Neurologii, 1, 45-54.

Kube, T., \& Rief, W. (2017). Are placebo and drug-specific effects additive? Questioning basic assumptions of double-blinded randomized clinical trials and presenting novel study designs. Drug Discovery Today, 22, 729-735. https://doi.org/10.1016/j. drudis.2016.11.022

Lacasse, J. R., \& Leo, J. (2015). Challenging the narrative of chemical imbalance. In B. Probst (Ed.), Critical Thinking in Clinical Diagnosis and Assessment (pp. 275-282). New York: Springer.

Le Noury, J., Nardo, J. M., Healy, D., Jureidini, J., Raven, M., Tufanaru, C., \& Abi-Jaoude, E. (2015). Restoring Study 329: efficacy and harms of paroxetine and imipramine in treatment of major depression in adolescence. British Medical Journal, 351, h4320. https://doi.org/10.1136/bmj.h4320

Linde, K., Berner, M. M., \& Kriston, L. (2008). St John's wort for major depression. Cochrane Database of Systematic Reviews, 4. https://doi. org/10.1002/14651858.CD000448.pub3

Lund, K., Vase, L., Petersen, G. L., Jensen, T. S., \& Finnerup, N. B. (2014). Randomised controlled trials may underestimate drug effects: balanced placebo trial design. Public Library of Science One, 9, e84104. https://doi.org/10.1371/journal.pone.0084104

Moncrieff, J., Wessely, S., \& Hardy, R. (2004). Active placebos versus antidepressants for depression. Cochrane Database of Systematic Reviews, 1. https://doi.org/10.1002/14651858.CD003012.pub2

Netz, Y. (2017) Is the comparison between exercise and pharmacologic treatment of depression in the clinical practice guideline of the American College of Physicians evidence-based? Frontiers in Pharmacology, 8, 257. https://doi.org/10.3389/ fphar.2017.00257

NHMRC (2015). NHMRC Statement: Statement on Homeopathy. Retrieved from www.nhmrc.gov.au [accessed 09.2017]

Osher, Y., \& Belmaker, R. H. (2009). Omeg-3 fatty acids in depression: A review of three studies. CNS Neuroscience \& Therapeutics, 15, 128-133.

Ostroff, R. B., \& Nelson, J. C. (1999). Risperidone augmentation of selective serotonin reuptake inhibitors in major depression. The Journal of Clinical Psychiatry, 60, 256-259.

Rabkin, J. G., Markowitz, J. S., Stewart, J., McGrath, P., Harrison, W., Quitkin, F. M., \& Klein, D. F. (1986). How blind is blind? Assessment of patient and doctor medication guesses in a placebo-controlled trial of imipramine and phenelzine. Psychiatry Research, 19, 75-86. https://doi.org/10.1016/01651781(86)90094-6

Ramel, W., Goldin, P. R., Carmona, P. E., \& McQuaid, J. R. (2004). The effects of mindfulness meditation on cog-
Twenty years after 'Listening to Prozac but hearing placebo' 
nitive processes and affect in patients with past depression. Cognitive Therapy and Research, 28, 433-455. https://doi.org/10.1023/B:COTR.0000045557.15923.96

Reuters (2015). Analysis of GSK's Seroxat antidepressant finds key data was held back. Retrieved from www.reuters.com [accessed March 16, 2017]

Rutherford, B. R., Wall, M. M., Brown, P. J., Choo, T. H., Wager, T. D., Peterson, B. S., Chung, S., Kirsch, I., \& Roose, S. P. (2016). Patient expectancy as a mediator of placebo responses in antidepressant clinical

Wojciech OronowiczJaśkowiak, Przemysław Bąbel trials. American Journal of Psychiatry, 174, 135-142. https://doi.org/10.1176/appi.ajp.2016.16020225

Rybakowski, J. (2011). Leki stosowane w chorobach afektywnych [Pharmacological treatment in affective disorders]. In M. Jarema \& J. Rabe-Jabłońska (Eds.), Psychiatria: podręcznik dla studentów medycyny [Psychiatry for medical students] (pp. 457534). Warszawa: Wydawnictwo Lekarskie PZW.

Siwak, S., Oronowicz-Jaśkowiak, W., \& OronowiczJaśkowiak, A. (2017). Efekt leczenia antydepresantami może sprowadzać się do wzmocnionego efektu placebo. Przegląd literatury [The effect of treatment with antidepressant drugs is equivalent to the enhanced placebo effect. The empirical support of the Irving Kirsch's theory]. In E. Bajek \& B. A. Nowak (Eds.), Choroby XXI w. - analiza wspótczesnej sytuacji zdrowotnej [Diseases of the 21st century - analysis of the current health situation] (pp. 133-141). Lublin: Wydawnictwo Naukowe Tygiel.

Sneed, J. R., Rutherford, B. R., Rindskopf, D., Lane, D. T., Sackeim, H. A., \& Roose, S. P. (2008). Design makes a difference: a meta-analysis of antidepressant response rates in placebo-controlled versus comparator trials in late-life depression. The American Journal of Geriatric Psychiatry, 16, 65-73. https://doi. org/10.1097/JGP.0b013e3181256b1d

Stahl, S. (1994). 5HT1A receptors and pharmacotherapy. Is serotonin receptor down-regulation linked to the mechanism of action of antidepressant drugs? Psychopharmacology Bulletin, 30, 39-43.

Viksveen, P., Relton, C., \& Nicholl, J. (2017). Depressed patients treated by homeopaths: a randomised controlled trial using the "cohort multiple randomised controlled trial" (cmRCT) design. Trials, 18, 299. https://doi.org/10.1186/s13063-0172040-2

Zhang, Z. J., Tan, Q. R., Tong, Y., Li, Q., Kang, W. H., Zhen, X. C., \& Post, R. M. (2008). The effectiveness of carbamazepine in unipolar depression: a doubleblind, randomized, placebo-controlled study. Journal of Affective Disorders, 109, 91-97. https://doi. org/10.1016/j.jad.2007.11.004 